\title{
The political economy of bovine tuberculosis in Great Britain
}

Article

Accepted Version

Bennett, R. (2017) The political economy of bovine tuberculosis in Great Britain. Revue Scientifique et Technique, 36 (1). pp. 105-114. ISSN 0253-1933 doi:

https://doi.org/10.20506/rst.36.1.2614 Available at https://centaur.reading.ac.uk/65754/

It is advisable to refer to the publisher's version if you intend to cite from the work. See Guidance on citing.

Identification Number/DOI: https://doi.org/10.20506/rst.36.1.2614 $<$ https://doi.org/10.20506/rst.36.1.2614>

Publisher: Office International des Epizooties

All outputs in CentAUR are protected by Intellectual Property Rights law, including copyright law. Copyright and IPR is retained by the creators or other copyright holders. Terms and conditions for use of this material are defined in the End User Agreement.

www.reading.ac.uk/centaur

\section{CentAUR}

Central Archive at the University of Reading 
Reading's research outputs online 


\title{
The political economy of bovine tuberculosis in Great Britain
}

\author{
R.M. Bennett
}

Economics and Social Science Division, School of Agriculture, Policy and Development, University of Reading, Reading RG6 6AR, United Kingdom

r.m.bennett@reading.ac.uk

\section{Summary}

A brief history of bovine tuberculosis (bTB) and its control in Great Britain is presented. Numerous diverse policies to control the disease in man, cattle and wildlife have been pursued over the last 100 years and many millions of pounds have been spent. After notable success in reducing the incidence and prevalence of bTB in cattle in GB from the 1950s to the mid-1980s, the number of cattle slaughtered has increased with increased geographical spread continually since that time with a high point of bTB incidence in 2008. This increase appeared to coincide with changing policy regarding the control of the disease in badgers with a more humane approach adopted and with strengthened protection for badgers through legislation. Indeed, much controversy has been involved in the debate on the role of badgers in disease transmission to cattle and the need for their control as vectors of the disease with various commissioned research projects, trials, public consultations and media attention. The findings of two social science investigations presented as examples showed that citizens generally believed that bTB in cattle is an important issue that needs to be tackled but objected to badgers being killed, whilst cattle farmers were willing to pay around $£ 17 /$ animal/year for a bTB cattle vaccine. It is noted that successes regarding the control of bTB in other countries have combined both cattle and wildlife controls and had strong involvement from industry working with government.

Keywords Bovine tuberculosis — Control - Policy. 


\section{A brief history of bTB policy in Great Britain}

\section{The fall of bTB in $G B$}

Bovine tuberculosis (bTB) could be described as the BSE of the late $19^{\text {th }}$ Century ${ }^{1}$ and was not identified as a different disease to human tuberculosis until 1882. Following its identification, three Royal Commissions were appointed to look into the disease between 1890 and 1911. However, nothing tangible was done to control bTB until the TB Orders of 1913/14 which allowed a health authority to slaughter an 'openly' affected animal. Numbers of cattle slaughtered under these orders increased year by year such that in 1929 some 15,500 cattle were slaughtered. By the 1930 s at least $40 \%$ of dairy cattle were thought to be infected with bTB ${ }^{2}$ with around 2,500 human deaths per year and much greater numbers of people suffering illness (in stark contrast to more recent times when bTB control in cattle has been described as 'irrelevant as a public health policy') $)^{3}$. A voluntary Attested Herd Scheme and milk pasteurisation were introduced in 1935 . However, by 1947 only $14 \%$ of cattle were in attested herds.

In 1950 an area eradication policy was pursued with compulsory testing of cattle, slaughter of those that tested positive and government compensation to cattle farmers. In addition, pasteurisation became routine and slaughterhouse inspections were increasingly put in place to protect public health. By 1960 the whole of GB was attested. The prevalence of bTB in cattle fell markedly during this period from some 23,000 cattle slaughtered due to the disease in 1935 to a low level in 1960 (data unreliable to give precise numbers of cattle slaughtered).

In 1971 bTB was identified in badgers ${ }^{4}$. The 1973 Badger Act provided protection for badgers but the Ministry of Agriculture, Fisheries and Food (MAFF) could grant licences to individuals to kill badgers to prevent disease spread. Over the $1975-82$ period gassing of badger setts was carried out by MAFF to control the disease (under the Conservation of Wild Creatures and Wild Plants Act 1975). The disease and number of cattle slaughtered continued to decline until the late 1970 s with 1979 recording the lowest prevalence $(0.49 \%$ of herds tested and $0.018 \%$ of cattle tested) and then remained at a low level until the mid-1980s when it started to rise again, with fewer than a thousand cattle slaughtered in $1980^{5}$. During this time, experiments at the government's Central Veterinary Laboratories had shown that infected badgers can pass infection to cattle ${ }^{6}$. However, in 1980 the Lord Zuckerman review responded to concerns that gassing of badgers was inhumane and it was stopped. Instead, 
from 1982-1985 there was a 'clean ring' policy of culling infected badger groups by trapping and shooting.

\section{The rise of $\mathrm{bTB}$ in $\mathrm{GB}$}

In 1986 there was the Dunnet review which introduced an 'interim strategy' which lasted until 1997, with badger culling only on farms where bTB was confirmed and where the source of infection was badgers. The 1992 Protection of Badgers Act provided additional protection for badgers in GB making it an offence to kill, injure, cruelly ill-treat or take a badger, or interfere with a sett ${ }^{7}$. By 1996 it was clear that this interim strategy was not working with bTB in cattle rising substantially and John Krebs chaired an Independent Scientific Review Group which reported at the end of 1997. As a result of this review, the Independent Scientific Group (ISG) was set up in 1998 which put in place an extensive Random Badger Culling Trial (RBCT). The trial continued for some years with the ISG reporting mixed results highlighting area effects and badger perturbation with a reduction in bTB incidence in some areas but concluding that badger culling was not thought to be economic.

It is worth noting that in 2003 the reactive component of the RBCT was stopped because bTB in some areas had increased and it was thought that this was due to badger perturbation as a result of culling. Arguably, the decision to cease this element of the RBCT resulted in a loss of trial data being available for subsequent analysis. Within the trial period the government undertook a review and consultation of bTB policy and in 2005 published the Government Strategic Framework for Sustainable Control of bTB in GB, providing a ten year vision which aimed to 'develop a new partnership' to slow down spread and reduce cattle incidence in high incidence areas ${ }^{8}$. In 2006, the government introduced new compensation 'table' values rather than $100 \%$ market values for compulsorily slaughtered cattle and introduced pre-movement bTB testing of cattle.

\section{Governance and the role of advisory committees}

During this period, GB government used a number of advisory boards to advise on bTB strategy and implementation. The TB Forum (a stakeholder group chaired by Defra) operated from 1999 to 2006. It was described by an Environment, Food and Rural Affairs Select

Committee $^{9}$ as "an arena for the repetition of entrenched views" with farmers' representatives on one side calling for a cull of badgers and wildlife groups on the other maintaining that 
badgers were largely not to blame for bTB and that a cull would achieve very little, with a Defra official refereeing an often heated and confrontational debate. In 2006, the TB Advisory Group (TBAG) was set up. There was also a bTB Husbandry Group (set up in 2006) and a bTB Science Advisory Board (set up in 2008). The government had also set up an England Implementation Group (EIG) for the Animal Health and Welfare Strategy in 2005 (later disbanded in 2009 and replaced with the Animal Health and Welfare Board for England), which largely steered clear of commenting on bTB policy in part fearing that the wide remit of EIG could become dominated by the issue.

A high point of bTB incidence was seen in 2008 with $6.4 \%$ of herds declared as 'new culture or lesion positive'. In July 2008 the then Defra minister announced that there would be no badger cull due to the uncertainty of success (Defra-commissioned research had highlighted the costs of badger culling in relation to the possible scenarios of bTB incidence in cattle, with some scenarios showing a worsening of bTB due to badger perturbation and others a net cost associated with badger culling in relation to the benefits ${ }^{10}$ ). However, the minister also announced a $£ 20 \mathrm{M}$ investment in vaccine development (in 2009/10 the Defra Badger Vaccine Deployment Project tested a BCG badger vaccine) with the long-term goal of eradicating bTB in GB. This goal was re-iterated in the TBAG 2009 report 'Towards Eradication',11 which marked a policy change from merely aiming to reduce the incidence and slow the spread of bTB in cattle ${ }^{12}$.

At this time, TBAG was disbanded and replaced by the TB Eradication Group (TBEG) which in turn (in 2012) was replaced by TBEAG (TB Eradication Advisory Group) for England which advised the newly formed Animal Health and Welfare Board for England (AHWBE) which was set up in 2011. Wales (and, to some extent, Scotland) had similar devolved bodies.

In 2011, Defra produced a TB eradication program for England which it described as 'a comprehensive and balanced package of measures to tackle TB in cattle, badgers and other animals, including the Government's view that it is strongly minded to allow a science-led cull of badgers in the worst affected areas ${ }^{, 13}$. A top priority of the program was to produce a cattle vaccine and an oral badger vaccine but recognizing that this would take some years. However, a BCG-based injectable badger vaccine had been available for use in GB since 2010 but with little take up by cattle farmers or others (despite some funding available from government). In 2013, a somewhat controversial pilot cull of badgers was introduced into 
two pilot areas of England, in west Gloucestershire and west Somerset. Badger and other wildlife and animal welfare groups were generally against the trial. The primary aim of these trials was to assess the effectiveness, safety and humaneness of culling using 'free shooting' (i.e. rather than trapping in cages and then shooting). The Welsh Government suspended a badger cull programme in 2011 and replaced it with a five year trapping and vaccination programme.

\section{Role of the media}

The issue of badger culling has been a sensitive and political one for some decades, arguably with the media (especially newspapers) helping to stoke public concerns. Two newspaper articles provide good examples of this. The first reports on the government's consultation on badger culling in 2005. This article was in the Independent newspaper (16 ${ }^{\text {th }}$ December 2005$)$ with substantial space given to the story both inside the paper and with virtually the whole of the front page dominated by a picture of a badger and a large print headline which read "The Culling Fields" and two sub-headings "Mass slaughter plan for badgers provokes outcry" and "Animal groups deny that cull will ease TB crisis". The main headline is an emotive play-onwords of 'The Killing Fields' which is a well-known 1984 film about the Cambodian War in the 1970s and Pol Pot's cleansing campaign which killed 2 million 'undesirable' civilians. This could be interpreted as suggesting that badger culling is akin to ethnic cleansing.

The second article was in the Guardian's 'i' newspaper $\left(14^{\text {th }}\right.$ September 2013$)$ and reported on the pilot badger culls in England referred to previously. Again, the article was accompanied by a picture of a badger together with members of an 'anti-badger cull patrol' in west Somerset. The article was headlined "We heard four shots, a scream, then grunting ... then silence". In fact, the headline was taken from a local patrol member who is quoted as saying "We heard three or four shots, which lasted three to five seconds, then grunting, then silence... I know what death sounds like". Again, arguably, this is very emotive reporting almost entirely from the perspective of protestors against the pilot cull, and with an emotive and perhaps anthropomorphic description of badgers 'screaming'.

The 2005/6 public consultation on badger culling received over 47,000 letters, 10,000 texts and 13 petitions with only $4 \%$ of people in favour of culling (http://news.bbc.co.uk/1/hi/sci/tech/5172360.stm). YouGov polls on badger culling since 2012 have found more people opposed to a cull than supporting one 
(httpsi//yougov.co.uk/news/2014/09/11/two-years-badger-cull-remains-unpopular), although public opinion appears to have softened somewhat in this regard over the last ten years.

Following public consultation, in April 2014 Defra published its 'Strategy for achieving Officially Bovine Tuberculosis Free status for England'. The main elements of this are: for England to be Officially TB Free (OTF) by 2038 with some parts being OTF by 2025; the pursuance of a risk area strategy; culling of badgers in endemic areas and $£ 24.6 \mathrm{M}$ for development of cattle and badger vaccines - although these are referred to as "still many years away" ${ }^{\prime 4}$, although in 2015 cattle vaccine/DIVA field trials are programmed to take place.

A key element of this strategy is the 'edge' area which is one of three types of defined bTB risk area identified in the strategy - 'high risk area' (HRA; $0.1 \%$ herd prevalence), 'edge' (1\% herd prevalence and increasing) and 'low risk area' (LRA; 9\% herd prevalence). The 'edge' is a geographical area at the edge of annual testing areas in England where bTB is not thought to be endemic but where infection is either spreading or is at risk of disease spread in the short to medium term ${ }^{15}$. Edge areas are subject to 'enhanced cattle controls' and annual testing. In addition, a voluntary risk-based cattle trading scheme was introduced ${ }^{16}$.

\section{The current situation}

Despite the extensive activities undertaken over the last few decades, in 2015 bTB continues to increase its geographic spread in England and Wales without satisfactory resolution, although Scotland (with a historically low and stable incidence of bTB) became OTF in 2009. Indeed, the costs associated with bTB in GB have increased markedly from an estimated $£ 25$ million in $1998 / 99^{17}$ to over $£ 108$ million in $2008 / 9^{18}$ and likely continue to be in access of $£ 100$ million per annum today. The number of cattle herds that are not OTF has increased to over 8,500 in 2014 (from 5,220 in 2004 and 1589 in 1996) with new herd incidents of over $4,700 .^{19}$

The bTB debate continues to revolve around a number of 'thorny' issues. These include the contribution to infection of cattle to cattle spread and badger (and other wildlife) to cattle spread, the efficacy of bTB cattle testing, the efficacy of cattle and badger vaccination, the acceptability, efficacy and cost of badger culling, the potential of farm biosecurity measures to reduce spread, the role of government and partnership working with stakeholders 
(especially the cattle industry), the polarisation of opinion with often heated, emotive debate and apparently conflicting evidence - for example, the ISG's conclusion that a badger cull was too costly and impractical whilst the Select Committee on Agriculture ${ }^{20}$ stated that it could have a "significant effect on reducing TB in cattle". Pfeiffer $(2013)^{21}$ looks back on the previous 20 years of the problem of bTB in GB and concludes that an 'integrated risk governance perspective' is needed which includes participatory components by stakeholders and which takes account of the drivers of human behaviour (the importance of the latter to livestock disease control is well highlighted by Olmstead and Rhode, $2015^{22}$ ).

\section{Social science research case studies}

This section presents two case-study examples from 22 (published) economic and social science studies of bTB in GB identified by a Defra review in $2013^{23}$.

\section{Public attitudes to badgers and bTB in cattle}

A long standing issue in bTB control in GB has been the control of badgers as a source of cattle infection. A number of research studies have been commissioned by government to assess the role that badger control may play in reducing bTB and stakeholders' views, particularly in relation to badger culling in its various forms (trapping and shooting, gassing, 'free' shooting). A major problem in this regard has been that historically British citizens have seen the badger as a much loved wildlife species that they have been exposed to since childhood through literature such as "The Wind in the Willows' ${ }^{24}$ and through wildlife groups (the badger is the emblem on the logo of the 47 Wildlife Trusts in the UK) and wildlife programs on their television screens (e.g. the BBC's Springwatch programme).

In 2007/8 Defra commissioned a study to assess the value that people in England and Wales give to badger populations in the context of bTB and possible badger culling ${ }^{25}$. The study involved a choice experiment (CE) survey of 400 telephone interviews using a stratified random sample of households in England and Wales. The interview questionnaire contained (i) questions about respondents' experiences of badgers and their attitudes regarding the management of badgers (ii) an information statement about badgers and bTB, an explanation of the choice exercise and the choice sets for people to express their preferences (iii) an openended question asking respondents to explain the reasoning behind their choices (iv) a further series of attitudinal questions which on respondents' attitudes to badger management and bTB and (v) personal questions about the respondent and their household. The design of the 
choice experiment involved four attributes (size of the badger population, cattle slaughtered due to bTB, badger management strategy and household tax) at four levels with eight choice sets of two alternatives presented to respondents (see Table I for the attribute levels and Table II for an example choice set).

From the choices made by respondents estimates were derived (using a Conditional Logit model) for the trade-offs that people are prepared to make between the various attributes (i.e. their 'value' in terms of other attributes which include a money payment).

The main findings of the study in terms of citizens' attitudes to bTB in cattle and control of badgers is shown in Figure 1. Ninety-two per cent of people agreed that controlling bTB in cattle is important but they were not sure whether this should be done by controlling badger populations. Seventy-three percent objected to badgers being intentionally killed but $87 \%$ thought it acceptable to control badger populations if it could be done without killing whilst just over half of people thought that a limited or temporary cull of badgers was acceptable if it solved the bTB problem. It was estimated that respondents would be willing to pay a mean of $£ 0.10$ per household per year for an extra 100,000 badgers in the badger population (within population limits of 100,000 to 400,000$), £ 1.52$ per household per year for every 10,000 reduction in cattle slaughtered due to bTB and $£ 68.31$ per household per year not to have badger culling.

Aggregating these values for England and Wales (21.7 million households) gives a willingness to pay per additional badger in the population of $£ 22 /$ year and $£ 3,298$ per animal for a reduction in cattle slaughtered each year due to bTB. This would value a reduction in the badger population from the current 300,000 to 100,000 animals at $£ 4.4$ million per year and a reduction in cattle slaughtered due to bTB from 24,000 per year to zero at $£ 79$ million per year. Badger culling would appear to be very important to people with a very high aggregate willingness to pay of $£ 1,480$ million/year for England and Wales. It is likely that people have overstated their willingness to pay wishing to make a 'protest vote' because of the highly emotive nature of badger culling with strong feelings against it.

\section{The value of a bTB cattle vaccine to farmers}

Cattle vaccination is another area of intense debate in relation to bTB control and substantial sums of public money have been spent in pursuit of a practical and efficacious cattle vaccine. 
Defra commissioned a study in 2010/11 to explore farmers' attitudes towards and willingness to pay for a bTB cattle vaccine ${ }^{26}$. The study involved a telephone interview survey of 300 cattle farmers in annually -tested areas in England and Wales stratified according to whether farmers were dairy or beef and whether they had had a bTB breakdown in the previous five or ten years or not.

The questionnaire administered to farmers was divided into eight parts: (i) farm information (size and type of herd etc.); (ii) information relating to bTB on the farm; (iii) attitudinal statements and questions concerning bTB risk, bio-security etc; (iv) an information statement about bTB and a possible cattle vaccine; (v) a choice experiment exercise (containing a description and explanation of what the respondent should do with eight randomly allocated choice sets presented to them); (vi) a contingent valuation question; (vii) an open-ended debriefing question (asking respondents to explain the reasoning behind the choices they made) and follow-up attitudinal questions relating to their WTP; and (viii) personal details of the farmer and the farm family.

The survey used both contingent valuation and choice experiment methods to elicit farmers' willingness to pay for a bTB cattle vaccine with specific attributes. These attributes were: vaccine effectiveness in terms of the ability of a vaccine to prevent a farm having a bTB breakdown (risk of breakdown); vaccine effectiveness in terms of the ability of a vaccine to reduce the severity of a breakdown (i.e. reduction in the number of reactor cattle); the level of insurance or 'loss recovery' associated with a vaccine where a vaccine fails to prevent a bTB breakdown; and the cost per dose per animal of the vaccine.

Table III shows the levels for each attribute and an example of a choice set. The first attribute was given four possible levels providing reductions in the probability of a farm having a bTB breakdown of $20 \%, 40 \%, 60 \%$ or $80 \%$. The second attribute was also given four possible levels for reducing the severity of a breakdown of $20 \%, 40 \%, 60 \%$ or $80 \%$ (i.e. that the number of reactor cattle would be reduced by these percentages). The third attribute - the extent to which the farmer was covered by insurance for total losses due to bTB - was given five levels of $0 \%, 40 \%, 60 \%, 80 \%$ and $100 \%$. The fourth attribute - price of the vaccine was given five levels of $£ 5, £ 10, £ 15, £ 20$ and $£ 30$ (based on likely vaccine prices and pilot survey responses). 
In the contingent valuation question, respondents were provided with a brief scenario of a bTB cattle vaccine that was $90 \%$ efficacious and backed by a $100 \%$ insurance/loss recovery of total losses due to a bTB breakdown. The level of efficacy chosen was thought to be the maximum that would be credible to respondents. It was assumed in this case that the vaccine had to be administered annually. The CV question asked participants: 'Would you be willing to pay £x per animal per year for such a vaccine?’ Participants were first asked this question in relation to either $£ 10$ or $£ 15$ (chosen randomly). If they answered 'no' to this first question they were then asked whether they would be willing to pay a lower amount, either $£ 5$ or $£ 7$, respectively. If they answered 'yes' to the first question they were then asked whether they would be willing to pay a higher amount, either $£ 20$ or $£ 30$, respectively. Bid levels were chosen in the light of likely vaccine costs, focus group discussion of farmers' willingness to pay and bid values elicited in a pilot questionnaire.

Farmers' WTP for the vaccine attributes were estimated from the CE responses using a Bayesian mixed logit model following ${ }^{27}$. Farmers' WTP for the cattle vaccine specified in the double-bounded CV questions were estimated using the interval data estimation approach ${ }^{28} 29$ and using a Bayesian estimation method.

Results showed that $68 \%$ of farms had experienced a bTB breakdown. On average, farms reporting a bTB breakdown had 2.4 breakdowns in the previous five years, with an average of seven reactors in the most recent breakdown. The number of reactors or other animals slaughtered ranged from zero to 200. The average length of breakdown experienced by the farms was 34 weeks. More than two-thirds (68\%) of farms were clear of bTB at the time of the survey. Over $96 \%$ of farmers agreed that bTB was a major risk for the GB cattle industry, $61 \%$ felt that their farm had a high risk of a bTB breakdown, 39\% agreed that biosecurity on farms can greatly reduce the risk of bTB ( $40 \%$ disagreed), and over $71 \%$ thought there was not much that they could do to prevent their cattle getting bTB. Most farmers believed that there was a relatively high probability of their herds suffering a bTB breakdown as shown in Table IV. Indeed, most farmers felt there was at least a 50\% chance of their herd suffering a breakdown in any one year which was substantially higher than suggested by breakdown statistics in those areas.

Analyses of farmers' willingness to pay from the CE found that farmers had the highest willingness to pay for a vaccine that could reduce the risk of a breakdown, followed by the 
provision of loss insurance followed by the ability of a vaccine to reduce the severity of disease in terms of the numbers of reactors. Mean willingness to pay for a single-dose vaccine of $90 \%$ efficacy and backed by $100 \%$ insurance was $£ 55$ per animal. In contrast, mean willingness to pay from the contingent valuation estimate was $£ 17$ per animal per year for an annual vaccination which offered $90 \%$ efficacy and $100 \%$ insurance. Both estimates had relatively high standard deviations reflecting a large range of willingness to pay responses from farmers. Given the average lifespan of cattle, these values are comparable which provides some validity of their credibility.

\section{Conclusion}

This paper has briefly explored some aspects of the political economy of bTB in GB. It has provided a brief historical review, considered the influence of the media, changing governance and examples of the social science research related to the 'bTB problem'. Other countries, notably Australia, the USA (Michigan), New Zealand and the Republic of Ireland have all had some success in controlling bTB. However, each of these has combined control of the disease in wildlife (water buffalo, deer, possum and badger respectively) with control of cattle to cattle transmission and with substantial involvement of industry (including cost sharing), working in partnership with government. 


\section{Table I}

\section{Attributes and attribute levels used in the choice experiment}

\begin{tabular}{ll}
\hline Attribute & Attribute levels \\
\hline Badger population & $100,000,200,000,300,000,400,000$ \\
Management strategy & 1: trap and shoot badgers \\
& $\begin{array}{l}\text { 2: application of contraceptive to badgers } \\
\text { 3: current policy: badgers remain a protected species } \\
\text { 4: current policy plus provision of badger tunnels under } \\
\text { roads } \\
\text { Cattle with TB slaughtered }\end{array}$ \\
$\begin{array}{l}\text { per year } \\
\begin{array}{l}\text { Increase in tax per } \\
\text { household per year }\end{array}\end{array}$ & $£ 5 ; £ 20 ; £ 50 ; £ 100$ \\
\hline
\end{tabular}

\section{Table II}

Example of a choice set $*$

\section{Choice set}

A

Badger population (GB)

Management strategy

100,000

Trap and shoot badgers

10,000 cattle/year killed

$£ 20$

Increased tax per household
B

300,000

Current policy: badgers remain a protected species 20,000 cattle/year killed

$£ 20$

per year

* Respondents must choose their preferred choice set - either A or B.

** bTB: bovine tuberculosis

Table III

Example of experiment choice set showing attributes and their levels

\begin{tabular}{lccc}
\hline Vaccine attributes & A & B & C \\
\hline $\begin{array}{l}\text { 1. Vaccine effectiveness - reduction in the risk of a } \\
\text { breakdown }(20,40,60,80)(\%)\end{array}$ & 60 & 80 & 0 \\
$\begin{array}{l}\text { 2. Vaccine effectiveness - reduction in the breakdown } \\
\text { severity }(20,40,60,80)(\%)\end{array}$ & 80 & 80 & 0 \\
$\begin{array}{l}\text { 3. Insurance } / \text { loss recovery as \% of total financial loss } \\
\text { from bTB* }(0,40,60,80,100)(\%)\end{array}$ & 60 & 100 & 70 \\
$\begin{array}{l}\text { 4. Cost of vaccine dose }(£ 5, £ 10, £ 15, £ 20, £ 30) \\
\text { P }\end{array}$ & $£ 10$ & $£ 20$ & $£ 0$ \\
\hline
\end{tabular}

* bTB: bovine tuberculosis 


\section{Table IV}

Farmers' perceptions of the risk of their herd testing positive to bovine tuberculosis (bTB) in any one year (\% of sample in each category)

\begin{tabular}{lccc}
\hline Likelihood $(\%)$ & Whole sample & bTB breakdown & No bTB breakdown \\
\hline$>50$ & 30.0 & 38.5 & 12.1 \\
50 & 24.0 & 24.6 & 23.1 \\
33 & 12.2 & 12.3 & 12.1 \\
20 & 9.4 & 10.8 & 6.6 \\
10 & 8.7 & 5.1 & 16.5 \\
5 & 5.6 & 3.5 & 11.0 \\
$<5$ & 10.1 & 5.6 & 18.7 \\
\hline
\end{tabular}


Public attitudes to badgers and bTB

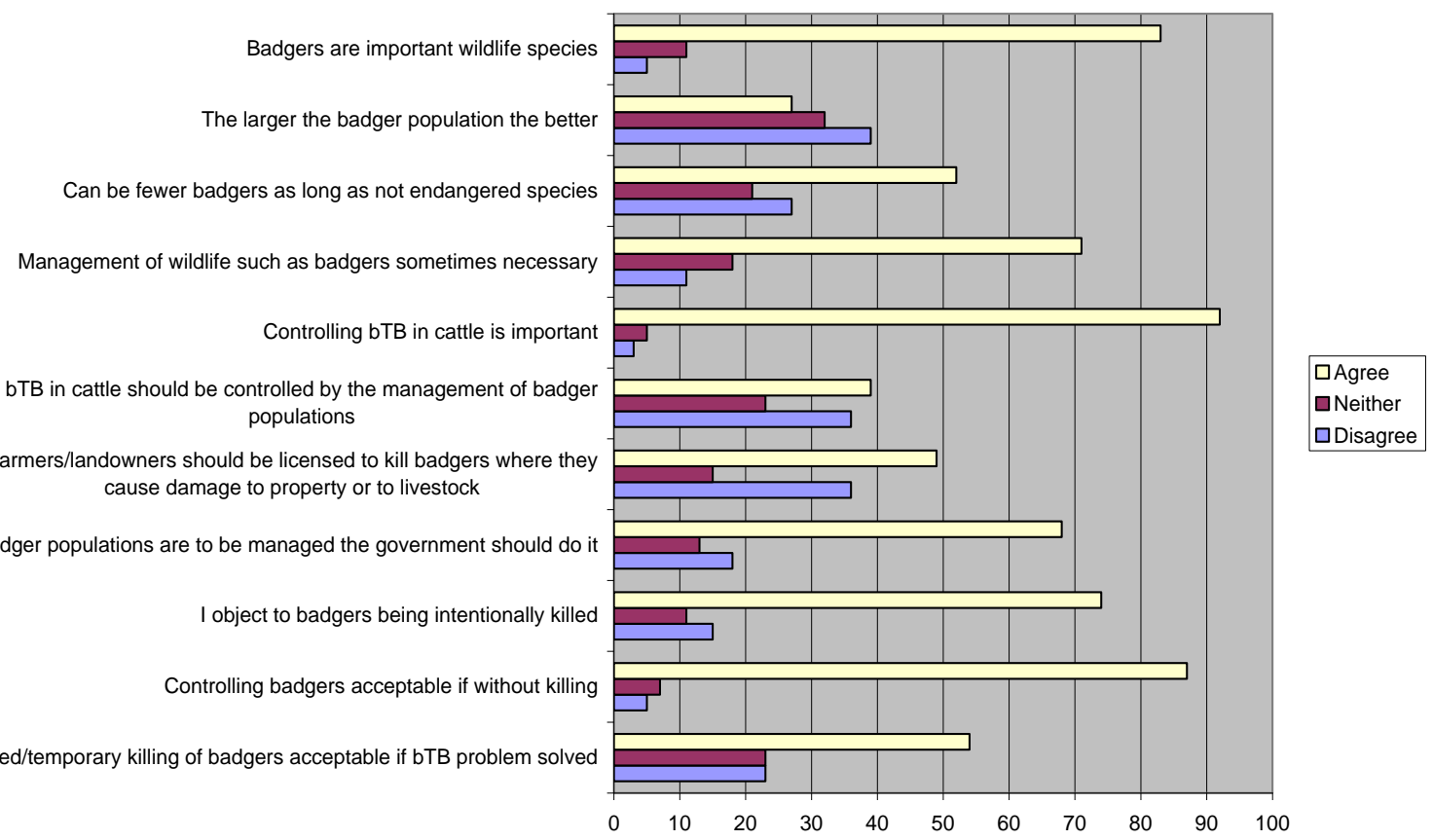

Fig. 1

Public attitudes to badgers and bovine tuberculosis (bTB) 


\footnotetext{
${ }^{1}$ Waddington K. (2002). - Safe meat and healthy animals: BSE and bovine TB. History and Policy. Available at: http://www.historyandpolicy.org/papers/policy-paper-04.html (accessed 11/04/2016).

${ }^{2}$ Economic Advisory Council (1934). - Report of Cattle Diseases Committee. H.M.S.O., London. Cmd. 4591.

3 Torgerson P.R. \& Torgerson D.J. (2010). - Public health and bovine tuberculosis: what's all the fuss about? Trends Microbiol., 18 (2), 67-72. doi: 10.1016/j.tim.2009.11.002.

4 Muirhead R.H., Gallagher J. \& Birn K.J. (1974). - Tuberculosis in wild badgers in Gloucestershire: Epidemiology. Vet. Rec., 95, 522-555.

${ }^{5}$ Goodchild T. \& Clifton-Hadley R. (2006). - The fall and rise of bovine tuberculosis in Great Britain. In Mycobacterium bovis infection in animals and humans (Thoen C. O., Steel J. H. \& Gilsdorf M. J., eds). Blackwell Publishing, lowa, 100-116

${ }^{6}$ Little T.W.A., Naylor P.A. \& Wilesmith J.W. (1982). - Laboratory studies of Mycobacterium bovis infection in badgers and cattle. Vet. Rec., 111, 550-557

${ }^{7}$ http://www.legislation.gov.uk/ukpga/1992/51/contents (last accessed 15/06/2015).

8 Defra (2005). - Government Strategic Framework for the Sustainable Control of Bovine Tuberculosis (bTB) in Great Britain. Department for Environment, Food and Rural Affairs, London

http://webarchive.nationalarchives.gov.uk/20130822084033/http://www.defra.gov.uk/animalh/tb/pdf/tbstrategicframework.pdf

${ }^{9}$ Environment, Food and Rural Affairs Select Committee (2003). - Seventh Report. Paragraph 50. Available at: http://www.publications.parliament.uk/pa/cm200203/cmselect/cmenvfru/432/43206.htm (accessed 15/06/2015)

10 Wilkinson D., Bennett R., McFarlane I., Rushton S., Shirley M. \& Smith, G. C. (2009). - Cost-benefit analysis model of badger (Meles meles) culling to reduce cattle herd tuberculosis breakdowns in Britain, with particular reference to badger perturbation. Journal of Wildlife Diseases, 45 (4), 1062-1088.

${ }^{11}$ Bovine TB Advisory Group (2009). - Bovine Tuberculosis in England: Towards Eradication. April 2009. http://www.bovinetb.info/docs/bovine-tuberculosis-in-england-towards-eradication.pdf

${ }^{12}$ Defra (2005). - Government Strategic Framework for the Sustainable Control of Bovine Tuberculosis (bTB) in Great Britain. Department for Environment, Food and Rural Affairs, London.

${ }^{13}$ Department for Environment, Food and Rural Affairs (DEFRA) (2011). - Bovine TB Eradication Programme for England PB13601
}

https://www.gov.uk/government/uploads/system/uploads/attachment_data/file/69443/pb13601-bovinetberadication-programme-110719.pdf

14 Department for Environment, Food and Rural Affairs (DEFRA) (2014). - The Strategy for achieving Officially Bovine Tuberculosis Free status for England PB14088.

https://www.gov.uk/government/uploads/system/uploads/attachment_data/file/300447/pb14088-bovine-tbstrategy-140328.pdf

${ }^{15}$ Department for Environment, Food and Rural Affairs (DEFRA) (2013). - Draft Strategy for Achieving

“Officially Bovine Tuberculosis-Free Status for England. PB 1394 . http://www.bovinetb.info/docs/draft-strategyfor-achieving-officially-bovine-tuberculosis-free-status-for-england.pdf

${ }^{16}$ The Bovine TB Risk Based Trading Group (2013). - Bovine TB Risk-Based Trading: Empowering Farmers to Manage TB Trading Risks.

https://www.gov.uk/government/uploads/system/uploads/attachment_data/file/193647/rbtg-final-report.pdf

${ }^{17}$ Defra (2005). - Government Strategic Framework for the Sustainable Control of Bovine Tuberculosis (bTB) in Great Britain. Department for Environment, Food and Rural Affairs, London.

${ }^{18}$ Department for Environment, Food and Rural Affairs (DEFRA) (2009). - Breakdown of bovine TB expenditure for GB 2008/09. Available at: http://www.bovinetb.info/docs/costs0809.pdf (accessed 15/06/15). 
${ }^{19}$ https://www.gov.uk/government/uploads/system/uploads/attachment data/file/433673/bovinetbstatsnotice-10jun15.pdf. (Last accessed 15/06/2015).

${ }^{20}$ Select Committee on Agriculture (1999). - Fifth Report. Badgers and Bovine Tuberculosis. Available at: http://www.publications.parliament.uk/pa/cm199899/cmselect/cmagric/612/61202.htm (accessed 15/06/2015).

${ }^{21}$ Pfeiffer D.U. (2013). - Epidemiology Caught in the Causal Web of Bovine Tuberculosis. Transboundary and Emerging Disease, 60 (Suppl. 1), 104-110. doi:10.1111/tbed.12105

${ }^{22}$ Olmstead A.L. \& Rhode P.W. (2015). - Arresting Contagion. Science, Policy, and Conflicts over Animal Disease Control. Harvard University Press. 480 pages.

${ }^{23}$ Bennett R., McFarlane I. \& Enticott G. (2013). - Socio-economic evidence relevant to the control of bTB in cattle. Report to Defra. University of Reading.

${ }^{24}$ Grahame K. (1908). - The Wind in the Willows. Methuen, London. 302pp.

${ }^{25}$ Bennett R. M. \& Willis K. (2008). - Public values for badgers, bovine TB reduction and management strategies. Journal of Environmental Planning and Management, 51, 511-524.

${ }^{26}$ Bennett R. \& Balcombe K. (2012). - Farmers' willingness to pay for a tuberculosis cattle vaccine. Journal of Agricultural Economics, 63 (2), 408-424.

${ }^{27}$ Train K. \& Sonnier G. (2005). - Mixed logit with bounded distributions of correlated partworths. In Applications of Simulation Methods in Environmental and Resource Economics (Alberini A. \& Scarpa R., eds), Springer, Dordrecht, 117-134.

${ }^{28}$ Hanemann M., Loomis J. \& Kanninen B. (1991). - Statistical efficiency of double-bounded dichotomous choice contingent valuation. American Journal of Agricultural Economics, 73, 1255-1263.

${ }^{29}$ Alberini A. (1995). - Efficiency vs bias of willingness-to-pay estimates: Bivariate and interval-data models. Journal of Environmental Economics and Management, 29, 169-180. 